\title{
A Comparison of Barcoding and RFID Technologies in Practice
}

\author{
Gareth R.T. White, Georgina Gardiner, \\ Guru Prabhakar, and Azley Abd Razak \\ Bristol Business School, University of the West of England, UK
}

\author{
Gareth.white@uwe.ac.uk; Georgina.gardiner@uwe.ac.uk; \\ Guru.prabhakar@uwe.ac.uk; Azley.abdrazak@uwe.ac.uk
}

\begin{abstract}
This research paper highlights inconsistencies in the way Radio Frequency Identification (RFID) is compared to existing barcoding technology and the lack of empirical evidence to support one's superiority over the other. Reference is drawn to the way in which RFID and barcoding technologies are represented in the literature. Time and motion studies were conducted in a distribution company's chilled warehouse where RFID technology had already been trialled and implemented on recyclable refrigerated food trays and in operation alongside barcoding systems. Attention was given to recording the number and nature of errors that each technology exhibited. This paper concludes that while RFID can deliver improved operational performance over traditional barcode systems, it is found to be less reliable in implementation. Hybrid systems may offer operational benefits over single-technology systems, but the cost of their complexity still needs to be examined.
\end{abstract}

Keywords: Barcode, RFID, warehouse, comparison

\section{Introduction}

"The advent of RFID systems is now attracting considerable attention from a number of UK retailers. It seems likely to enhance the ways in which retailers gather intelligence about their operations and their customer, it will require a fundamental review of their strategic planning processes and some commentators argue that it will bring transformational change throughout the supply chain” (Jones, Clarke-Hill, Hillier, \& Comfort, 2005, p. 396)

The advent of Radio Frequency Identification (RFID) technology has created a tidal wave of information, research and articles that praise this new technology. Major retailers such as Tesco, Marks \& Spencer, Wal-Mart, and Prada have already started utilizing this new technology in their supply chains, although some have adopted a wait and see approach (Fontelera, 2007; Furness,

Material published as part of this publication, either on-line or in print, is copyrighted by the Informing Science Institute. Permission to make digital or paper copy of part or all of these works for personal or classroom use is granted without fee provided that the copies are not made or distributed for profit or commercial advantage AND that copies 1) bear this notice in full and 2) give the full citation on the first page. It is permissible to abstract these works so long as credit is given. To copy in all other cases or to republish or to post on a server or to redistribute to lists requires specific permission and payment of a fee. Contact Publisher@InformingScience.org to request redistribution permission.
2005; Wyld, 2006). Some organisations have gone further and even introduced RFID tags in company identification badges in order to ease employee access to buildings and secure areas. While this seems a productive application of the technology, the fearful reaction of employees to privacy concerns has caused some projects to be cancelled (Hamblen, 2007). 
One of the biggest benefits RFID provides is that items can be traced across the supply chain and can be located in a warehouse within seconds. This is a very attractive advantage to businesses as they seek to make their supply chains more efficient and reduce waste, theft, and errors (Karkkainen, 2003; Prater, Frazier, \& Reyes, 2005; Ranky, 2006; "RFID still brings more questions", 2007; Sheffi, 2004; Wyld 2006). While adoption rates within supply chains have increased rapidly in the past few years (Furness, 2005; Ranky, 2006; Wyld 2006), there are still many retailers that have held back from RFID implementation as they believe that the technology is still not entirely proven and will wait to see the benefits other retailers can generate (Lai, Hutchinson, \& Zhang, 2005; Prater et al., 2005; Stevenson, 2004; Vijayaraman \& Osyk, 2006).

In recent years the visibility of RFID in the media and trade press has sharply increased mainly due to recent trials and implementation strategies by some high profile companies. Wal-Mart now requires its top 100 suppliers to have RFID tags on all products brought into their warehouses. Tesco, Sainsbury, and ASDA have all trialled RFID in their supermarkets but have not yet implemented a large-scale project. Marks and Spencer has also conducted RFID trials in its clothing and food line and has gone one step further by implementing an RFID system in the refrigerated food trays in all seven of the company's food depots (Jones, Clarke-Hill, Comfort, Hillier, \& Shears, 2005; Jones, Clarke-Hill, Hillier, Shears, \& Comfort, 2004; Vijayaraman \& Osyk, 2006).

This study compares RFID and barcode technologies employed in identical environments, thus taking an approach that not been previously undertaken. The study focuses upon the operational performance of the technologies in terms of scanning cycle time and equipment breakdowns.

\section{Literature Review}

A review of the literature reveals that very few empirical investigations have been undertaken to quantify the benefits of RFID and Barcoding technologies. The number of articles that discuss RFID technology and its adoption has risen from almost zero in the early 1990's to nearly nine thousand by 2005 . Of those studies that have been conducted so far only one dimensional barcodes were studied (Vijayaraman \& Osyk, 2006).

This does not appear to be an accurate representation of the technologies currently used in supply chains and firms. Have companies and researchers become so consumed with the hype that surrounds RFID that they have forgotten about the most widely used technology on this planet - barcoding, with five billion barcodes scanned each day across the world and already implemented across diverse businesses and product ranges (Wyld, 2006)?

Much of the literature promotes the benefit and cost savings that companies can gain by implementing RFID, from reductions in waste to more accurate stock information and faster scanning of inbound product (Atkinson, 2005; Clarke, Gosain, \& Thillairajah, 2005; "RFID still brings more questions," 2007; Vijayaraman \& Osyk 2006;). For example, the Institute for Grocery Distribution survey of 130 retailers, wholesalers, manufacturers, packaging suppliers, and logistics companies revealed that over two thirds of the major players in the UK's food and grocery industry believed that RFID would produce a wide range of benefits for them including greater speed and efficiency in stock operations (Clarke et al., 2005).

Karkkainen (2003) presents a breakdown of total savings that Sainsbury predicts to make if they implement a company wide RFID based tracking system. Improvements in inventory control at depots are predicted to return $£ 130,000$ of savings while reductions in in-store stock loss are expected to return over $£ 4$ million. Further advances in RFID technology that give improved operability and reduced costs, by combining the RFID and Input/Output technology in a single package, for example, should improve RFID's market position over barcoding technologies (DiSera, 2007). 
There are, however, additional costs and issues associated with implementing a project such as RFID that companies must consider. These include internationally agreed-upon operating standards, consumer privacy concerns, further system technological integration, data storage issues, software/hardware maintenance and upgrade costs, and employee training (Clarke et al., 2005; "E-Pedigrees," 2007; Fontelera, 2007; Furness, 2005; Lai, et al, 2005; Porter, 2006; Strauch, 2007; Vijayaraman \& Osyk 2006). Brewer (2007) warns against casual adoption of RFID while it remains in its technological infancy, recognising the cost and return on investment (ROI) advantages of tried and tested barcode technology, even suggesting that a hybrid RFID-barcode system is a viable compromise. Reynolds (2007) and O'Donnell (2007) report on expert opinion of RFID and barcode technologies noting that barcoding is here to stay.

Clarke et al. (2005) have also identified the inconsistencies between the portrayal of RFID and barcoding, noting that studies of the impact of RFID suggest most companies will not realise the expected financial benefits. Significantly, recent reports show that Walmart has not gained the benefits that were originally expected from the introduction of RFID technology ("Radio Interference", 2007). The number of RFID-enabled distribution centres and stores is considerably behind target and its general and administrative expenses have not decreased. Admittedly Walmart's initial targets for RFID rollout were ambitious, but this case serves to highlight the problem of applying technology before analysing and understanding the fundamental business problems and needs (Vizard, 2007).

\section{Technologies Studied}

Barcoding and RFID have emerged from the same roots, Auto Identification; this is a broad category of technologies that are used to identify objects, humans and animals. Other technologies linked to Auto-ID include optical character recognition systems, biometric systems, and smart cards (Wyld, 2006).

Even though RFID and barcoding come from the same technology family they are different in many ways (Wyld, 2006). There are numerous comparison charts that qualify the advantages and disadvantages of RFID and barcoding technology. Table 1 shows that RFID has many benefits over traditional barcoding systems (Wyld, 2006).

Table 1 RFID and Barcodes Compared (adapted from Wyld, 2006).

\begin{tabular}{|l|l|}
\hline \multicolumn{1}{|c|}{ Barcode } & \multicolumn{1}{c|}{ RFID } \\
\hline Require line of sight to be read & Can be read without line of sight \\
Can only be read individually & Multiple tags can be read simultaneously \\
Cannot be read if damaged or dirty & Can cope with harsh or dirty environments \\
Can only identify the type of item & Can identify a specific item \\
$\begin{array}{l}\text { Cannot be updated } \\
\text { Require manual tracking and therefore are } \\
\text { susceptible to human error }\end{array}$ & $\begin{array}{l}\text { New information can be over-written } \\
\text { Can be automatically tracked removing hu- } \\
\text { man error }\end{array}$ \\
\hline
\end{tabular}

\section{Radio Frequency Identification}

RFID is a revolutionary information exchange system that can create an environment in which every object can be automatically recognised, tracked, and traced from factory to shelf only using a single tag on each product item or pallet (Jones, Clarke-Hill, Shears, Comfort, \& Hillier, 2004; 
Jones, Clarke-Hill, Hillier, \& Comfort, 2005; Lai et al, 2005; Ranky, 2006; Sellitto, Burgess, \& Hawking, 2007). An RFID system typically comprises a transceiver, its associated antenna and the transponders (tags) that carry the data. With passive tags the reader transmits a low-power radio signal through the antenna that the tag receives via its own antenna to power an integrated chip. Using the energy it gets from the signal, the tag briefly converses with the reader for verification and the exchange of data. Once the reader receives the data, it can be sent to a controlling computer and stored in a database for further processing and analysis. Active tags perform in the same way as passive; the difference is that active tags transmit a signal through its antenna continually using power from an internal battery. This appears to be a segment of the RFID market that is growing particularly quickly (“Active RFID Market Surging," 2007).

While passive and active tags operate in very different ways, as shown in Table 2 (Wyld, 2006), they still carry the same information, known as the Electronic Product Code (EPC). This is a product numbering system that uses an additional set of numbers compared to barcodes and assigns each item manufactured with a unique product identification number. The EPC system is linked to an online database that increases the opportunity for information sharing. As the information is stored in only one place it makes changing information, such as item destinations and number of products, much easier. This also means that a product's path through a supply chain can be closely monitored and reviewed (Atkinson, 2005; Furness, 2005; Prater et al., 2005).

Table 2 Differences between Passive and Active Tags (adapted from Wyld, 2006).

\begin{tabular}{|ll|}
\hline \multicolumn{1}{|c|}{ Passive tags } & \multicolumn{1}{c|}{ Active tags } \\
Do not require a power source to operate & $\begin{array}{l}\text { Powered by an internal battery with a } \\
\text { finite lifespan }\end{array}$ \\
Short range & Long range \\
Sensitive to interference & Less sensitive to interference \\
Low data transmission rates & High data transmission rates \\
Can read few tags at once & Can read many tags at once \\
Reader needs to be aimed at the tag & Tags can be read without precise aiming \\
\hline
\end{tabular}

\section{Barcoding}

Barcodes are part of every product that we buy and has become the "ubiquitous standard for identifying and tracking products" (Wyld, 2006, p. 157) Traditional barcoding is coupled with the Universal Product Code (UPC) and every day accounts for billions of scans all over the world. According to a survey conducted by Zebra Technologies in 2006, over $96 \%$ of European companies cited improved efficiency as the main benefit of using barcoding. Other reasons that European companies gave for using barcodes were: increasing the accuracy of ordering and invoicing (32\%), cost reduction (26\%), and the fact that newer technology isn't ready yet (16\%) (“Accuracy tops UK”, 2006).

Within the Auto-ID family, a new two-dimensional system of barcoding has evolved which allows barcodes to hold more data than the traditional method. Figures 1 and 2 show the differences between one- and two-dimensional barcodes. Product data is encoded in both horizontal and vertical dimensions and, as more data is encoded, the size of the barcode can be increased in both the horizontal and vertical directions thus maintaining a manageable shape for easy scanning and product packaging specifications ("2D Barcodes Explained”, 2007; Shaked, Levy, Baharavl, \& Yen, 2001). 


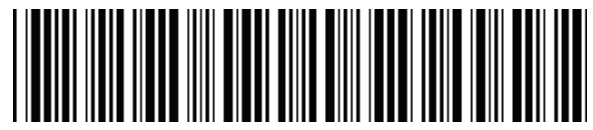

Conventional 1D barcode (Code 39)

Figure 1 Traditional one-dimensional
barcode

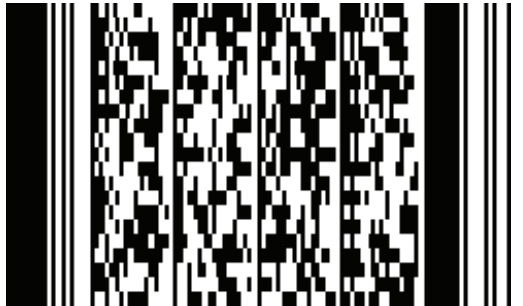

2D Barcode (PDF417)

Figure 2 Two-dimensional barcode

Two-dimensional barcodes are already being used for concert tickets by sending a barcode to a mobile phone and then scanning the message at the door by a laser gun. In Japan, mobile phones are being adapted to scan two-dimensional barcodes placed in magazines adverts. The barcode is scanned and connects the mobile to the internet and shows the user the film clip or plays the ring tones. Further developments in the lasers used to scan barcodes help improve the efficiency and speed in which barcodes can be scanned (Dearne, 2006; Ishii, 2004; Suzuki, 2006).

\section{Barcoding vs. RFID}

It has been shown that RFID tags can be adversely affected by demanding environments; for example, they are adversely affected if they are brought into contact with metal and liquids. The signal frequency that RFID uses is also subject to interference as they are commonly used by other technologies, and RFID standards as yet have not assigned a lone frequency for RFID transmissions (Clarke et al, 2005; Forcino, 2004; Ranky, 2006)

Barcodes, though, can be printed on durable materials and are not affected by substrate materials or electromagnetic emissions, all of which lend them a competitive edge in some industries and environments. Improvements in how barcodes are printed are evolving all the time as manufacturers strengthen the barcode system. Two-dimensional barcodes can be read even when damaged, so this further shortens the gap between the two technologies ("Barcode scanners", 2007; Dover, 1995). Developments in the range at which barcodes can be scanned similarly reduce the apparent performance gap between RFID and barcoding ("Wide ranging barcode scanner," 2007). It is questionable why there has been no significant research around these developments that can purportedly improve the quality and performance of existing systems.

\section{Organisation Studied}

In order to retain company anonymity, the organisation will be referred to as company XXXX.

XXXX currently provides end-to-end supply chain solutions for a range of companies in the United Kingdom. They operate over 35 sites for companies that include Marks \& Spencer, British Airways, Carlsberg, and Kingfisher Health. The operation moves over $£ 10$ billion pounds worth of merchandise every year.

Marks \& Spencer, in conjunction with XXXX (the logistics company contacted to perform Marks $\&$ Spencer's food distribution), has implemented an RFID system within its refrigerated food distribution chain. This system has been chosen to replace the existing barcode system that has been in use for many years. After extensive trials at one of the depots, the decision was taken to implement an RFID system across the depot network; the project would start by introducing item level tagging on recyclable green food trays that account for $61 \%$ of items moved from supplier.

A combination of passive tags and mobile readers were adopted during the implementation process in order to keep down costs and the volume of information that the tags produce to a level that 
was deemed manageable with the company's existing information system. The entire supply chain is continuing to work together in order to increase the supplier adoption rate from the initial required rate of $75 \%$, to the new target of over $90 \%$. At the time this research was conducted, 1.4 million RFID tags were scanned in the depots every week, with a $99.9 \%$ recorded accuracy rate.

\section{Methodology}

\section{Research Problem}

The literature discussed above highlights the little attention that has been paid to barcode technology over the last five years. While RFID has received a significant amount of positive publicity, we are beginning to see that in some instances it has not been capable of delivering the intended benefits. Most recently some commentators have recognised barcode technology as still having a place in modern supply chains. The success of RFID implementation is often discussed in terms of cost effectiveness or return on investment but this is a measure that favours barcode by comparison since it is a mature technology. Furthermore, the costing and accounting methods employed by those organisations may prohibit the direct comparison of RFID or barcode adoption with other organisations. Other discussions revolve around the robustness of RFID technology particularly in harsh environments, and the relative speed and accuracy of RFID over barcode.

These factors make unbiased comparison of the two technologies virtually impossible and may be contributing to the delay in RFID uptake in many organisations. This study compares RFID and barcode technologies employed in a single organisation in their chilled warehouse. This provides a direct comparison of the two technologies in identical environments, which has not been undertaken in previous studies. The study focuses upon the operational performance of the technologies in terms of scanning cycle time and equipment breakdowns. Reports in the literature lead us to expect RFID to deliver improved scanning speeds over barcode but to be susceptible to equipment breakdown brought about by operating in the chilled environment.

\section{Measurement and Sampling}

Data were collected in a chilled warehouse by conducting time and motion studies of operators using both RFID and barcode technology to scan products delivered in stackable plastic trays. Operators were timed using a stopwatch for each scanning cycle. Each cycle began when the scanning device was activated and ended when a stack of trays was successfully scanned. Errors and problems that were observed during the scanning process were recorded and are presented in the form of pareto charts.

Measurements were taken during the morning shift period between the times 7:00am and 9:00am on Sundays, Mondays and Tuesdays. The warehouse's planning documents were used to identify these days and times as being typical periods of consistent levels of organisational activity.

Convenience sampling was used when selecting the sample size. Twenty five employees had been fully trained on both barcoding and RFID scanning equipment and were the subject of the observations; their ages ranged from 21 to 48. Two of the participants declined to participant in the experiment. In order to avoid biasing or pressuring employees that took part in the research they were not requested to give reasons for choosing not to take part. Three employees were on holiday, leaving 20 participants who signed a confidentiality agreement and formed the group that were observed during the study. This study has advantages over other similar studies since the observed workforce is low enough in number to allow observation of the entire population of warehouse employees and thus negates the necessity to use a sampling strategy. 


\section{Findings}

To ensure that no subjects were adversely skewing the data, further analysis was required upon each subject's performance. A histogram of individual operator performance identified subjects 4, 14 and 16 as anomalous, taking longer than other subjects to perform the task. Removal of these subjects' data was found not to alter the overall statistical analysis significantly.

Figures 3 and 4 show the difference between the times taken to perform the operation using RFID (9.669 seconds average) and barcode scanning (24.479 seconds average).

They show that not only is RFID a faster operation but also more consistent (Std Dev $=3.0134$ ) than barcoding (Std Dev = 3.6858). This supports the view that RFID can deliver measurable operational benefits, faster cycle times result in more throughput, productivity benefits and lower product search times.

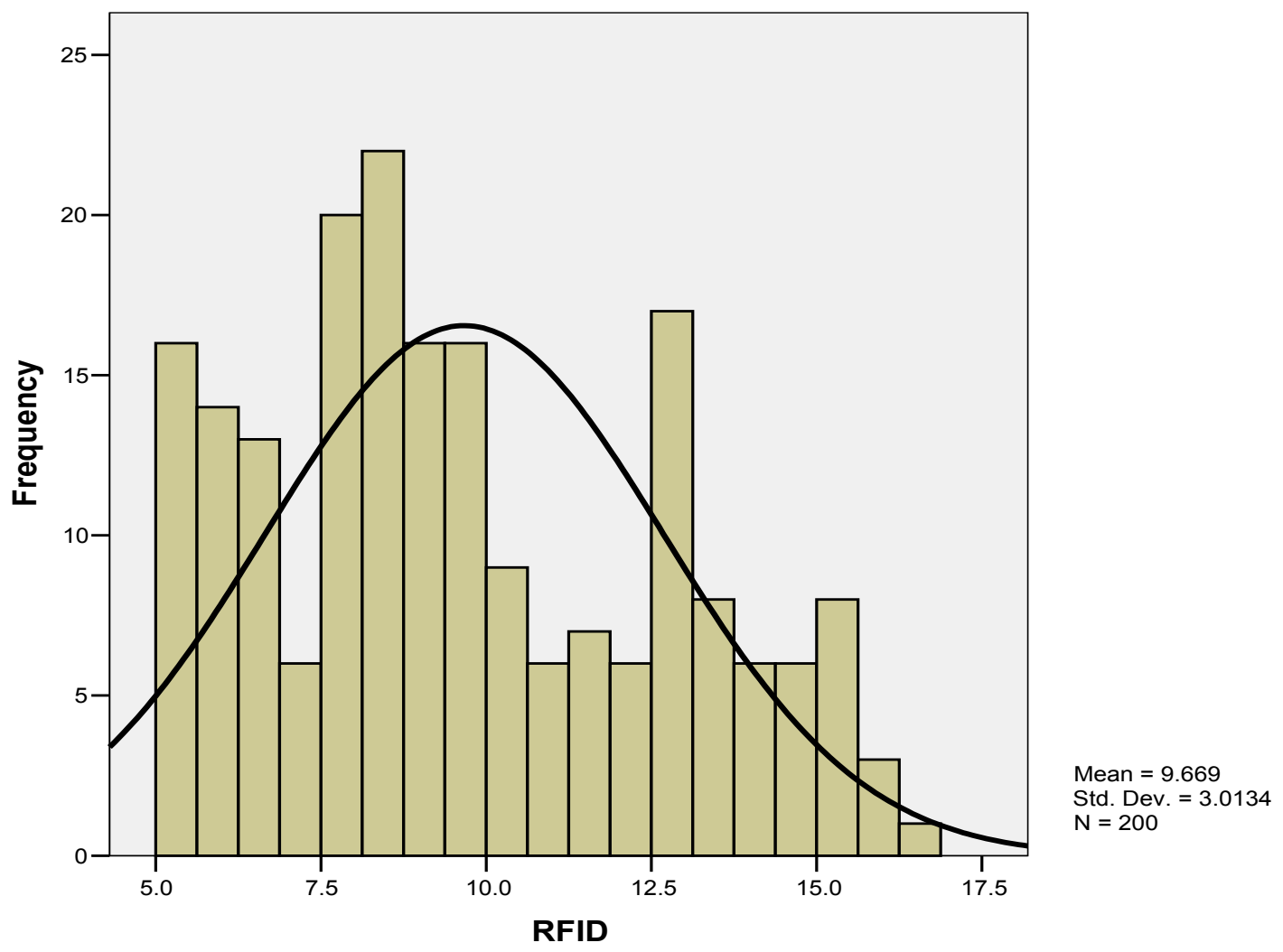

Figure 3 Frequency of RFID Scanning Times. 


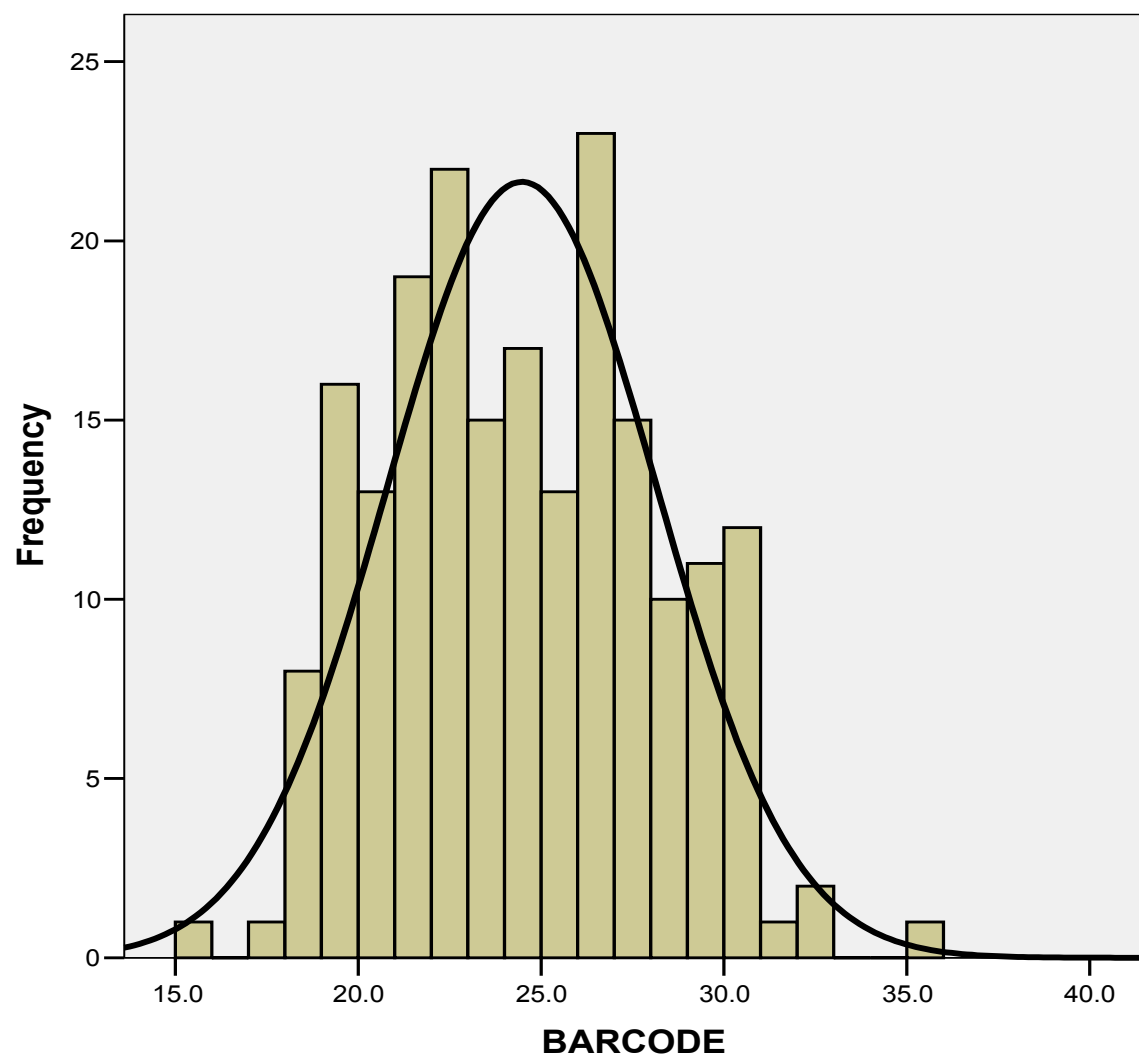

Mean $=24.479$

Std. Dev. $=3.6858$

$\mathrm{N}=200$

Figure 4 Frequency of Barcode Scanning Times.

Table 3 Descriptive Statistics of Each Day's Data.

\begin{tabular}{|l|l|l|l|l|l|}
\hline & N & Minimum & Maximum & Mean & Std. Deviation \\
\hline Sunday_RFID & 80 & 5.0 & 15.7 & 9.520 & 2.8769 \\
Sunday_Barcode & 80 & 18.4 & 35.4 & 24.895 & 3.8661 \\
Monday_RFID & 60 & 5.2 & 15.7 & 9.182 & 2.8426 \\
Monday_Barcode & 60 & 15.3 & 31.2 & 24.167 & 3.7321 \\
Tuesday_RFID & 60 & 5.0 & 16.8 & 10.357 & 3.2731 \\
Tuesday_Barcode & 60 & 18.5 & 32.6 & 24.237 & 3.3889 \\
Valid N(listwise) & 60 & & & & \\
\hline
\end{tabular}

Table 3 shows the level of consistency of each technology over the period of observation. The mean Barcode measurements range from 24.167 to 24.895 seconds (3\%) and the mean RFID measurements range from 9.182 to 10.357 seconds $(12.8 \%)$. Contrary to the analysis in Figures 3 and 4, this indicates that RFID is in fact less consistent than barcoding over a period of time. In fact, while barcoding delivers a greater range of scanning cycle times, the average cycle time shows less variation over time, whereas RFID cycle times are more localized around the mean but 
the mean value tends to vary more than that of barcode. As an example of the variation in mean, it is interesting to observe that the Tuesday RFID measurements indicate a notable increase in the maximum observed time, thus raising the mean observed cycle time by approximately $10 \%$. Further investigation shows that the RFID process experienced a high degree of equipment failures during this time; this also contributes to the variation in mean cycle time over the period of observation.

\section{Analysis of Scanning Errors \& Equipment Failures}

A review of the time and motion study data and observations revealed that there were numerous variables that were affecting both the RFID and barcode timings that were difficult to predict.

The problems observed with RFID were:

- $\quad$ Broken RFID and tag equipment;

- User errors regarding the movement of the RFID wand;

- Broken wheels in the stack requiring the subject to move themselves; physically in order to scan entire stack; and,

- Misread tags in the stack resulting in a warning sound making the subject look at the screen and stop scanning.

The problems observed with barcoding were:

- Missing labels on outside of the tray requiring the subject to scan the barcode of the product inside the tray;

- Unreadable labels requiring the subject to scan the product inside the tray

- Broken scanning equipment; and

- User error in which the subject scans the barcode incorrectly or is slow at the task.

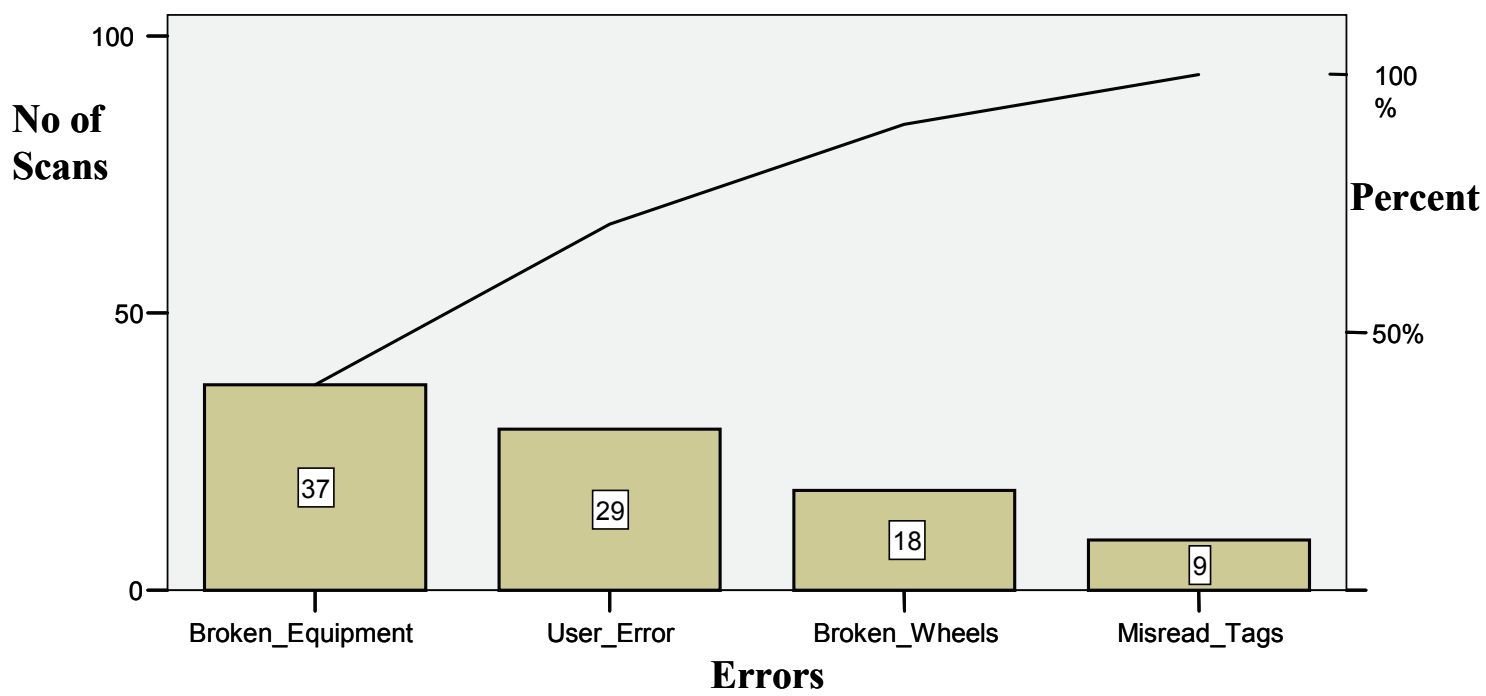




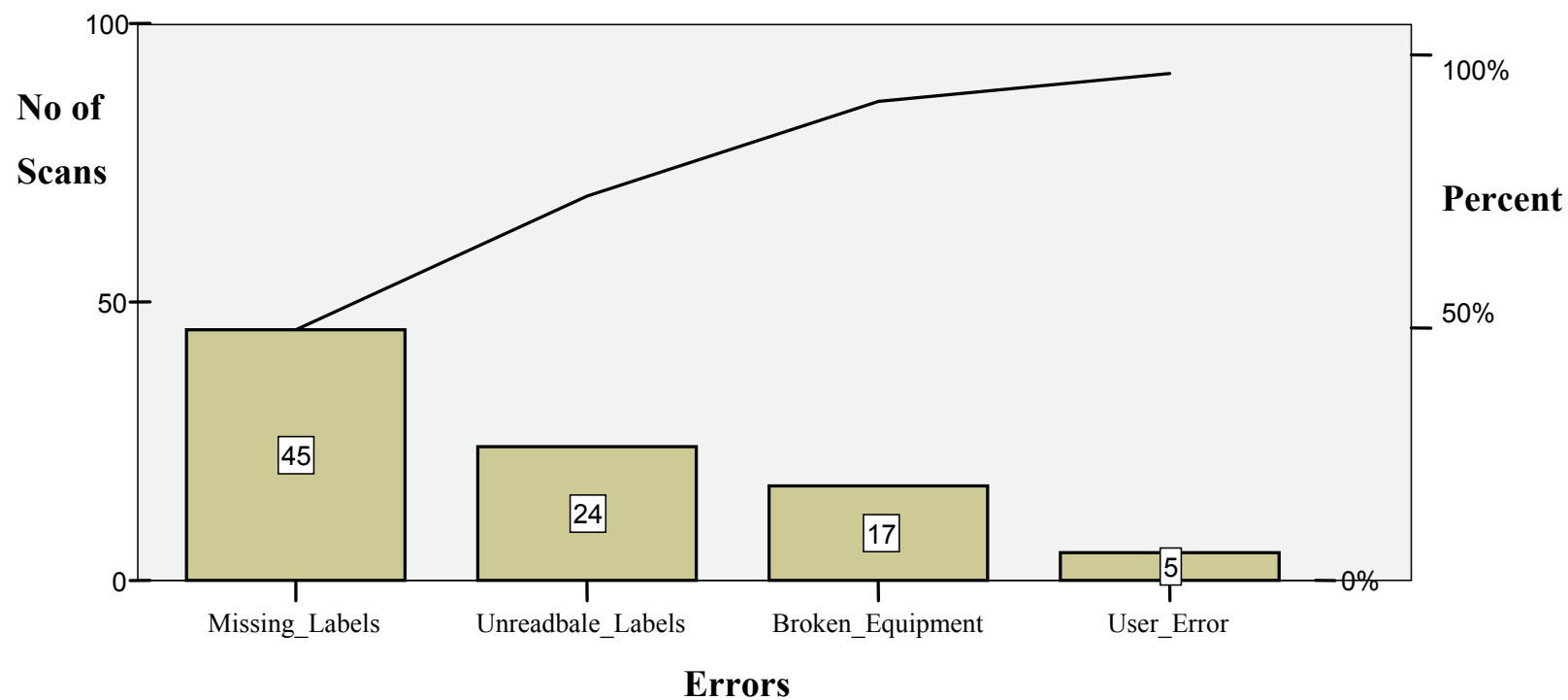

Figure 6: Errors in Barcode Scanning

From Figures 5 and 6, it is clear to see that both RFID and barcodes experienced a variety of errors during the 200 timings taken. Barcodes had a $45.5 \%$ error level equalling 91 errors within the 200 timings taken, and RFID had a $46.5 \%$ error level equalling 93 errors within the 200 timings taken. This indicates that RFID is prone to marginally more errors during the scanning process.

The significant number of 'broken equipment' errors for RFID (37\%) reinforces some of the studies identified in the literature describing the technical problems that RFID faces in real-world environments. Barcoding, while still subject to technical problems (17\%), is significantly more robust in this particular application.

RFID was also observed to suffer from significantly more user errors than barcoding: 29 errors as opposed to 5 errors. This perhaps indicates the maturity of barcode technology that has been established and developed over many years. Barcoding problems center around missing or damaged labels and suggest that successful barcoding will require effort to integrate suppliers and ensure that minimum standards for labeling are agreed and achieved.

\section{Conclusion}

This study provides a comparable analysis of RFID and barcoding technologies in practice in a single organisation in a chilled operating environment. The findings support much of the existing research and give a clear picture that RFID can deliver more rapid scanning times than barcode scanning. The literature suggests this as one of RFID's many benefits since tags can be scanned without being in the user's line of sight. This makes it immediately preferable over barcode technology in the majority of operational environments where rapid throughput of product is of paramount importance, such as into and out of chilled warehouses. Recent advances in two dimensional barcodes and laser scanning equipment, however, could help improve the time it takes for barcodes to be scanned and further empirical analysis of this particular technology is required. 
This research also agrees with our expectations in finding that RFID scanning is prone to having a higher frequency of equipment breakages in this particular harsh environment although it is less sensitive to operator errors than barcode. The equipment failures that were observed contributed significantly to variation in the mean observed scanning cycle time. Resilience to operator errors indicates that RFID may be an easier technology to adopt from a workforce-training perspective, and this may improve its attractiveness and cost-effectiveness if training costs are included in adoption costs.

Our findings also support the notion of hybrid RFID-barcode systems. Such a system would employ a particular technology in a specific area to take advantage of its relative cost effectiveness or robustness. It is not clear whether the additional complexity of such hybrid systems may increase the total system cost to a degree that exceeds the operational or cost benefits that the individual technologies may deliver. Future studies of hybrid systems should examine this cost of complexity.

\section{Limitations and Future Research}

While this study provides a valuable comparative analysis of RFID and barcoding the results are generalisable within the specific operational environment of a chilled warehouse. The study provides no account of the cost effectiveness or return on investment of these technologies since individual organisational costing and accounting methods may hide or cloud the total costs involved.

Further empirical evidence needs to be gathered to investigate the real-world effectiveness of both technologies in a range of operational environments. Furthermore, the rapid advances made in both technologies insist that further comparative studies are made throughout their maturation, particularly RFID.

\section{Acknowledgements}

The authors wish to extend their thanks to the editors and referees for their help and advice in developing this paper.

\section{References}

2D Barcodes Explained. (2007). Retrieved $11^{\text {th }}$ March 2007, from http://www.barcodeman.com/faq/2d.php

Accuracy tops UK. (2006). Retrieved $2^{\text {nd }}$ March 2007 from http://www.itrportal.com/absolutenm/templates/articlebarcode.aspx?articleid=3767\&zoneid $=48$

Active RFID market surging. (2007). Network World, 24 (31), 10.

Atkinson, W. (2005). Tagged: The risks and rewards of RFID technology. Risk Management. 12 (7), 86-92.

Barcode scanners. (2007). Wasp Technologies. Retrieved 5th March 2007 from http://www.waspbarcode.com/scanners/

Brewer, M. (2007). RFID adoption hurdles start to crumble. Wirelessdesignmag.com, October, 3-4.

Clarke, D., Gosain, S., \& Thillairajah, V. (2005). Realizing the promise of RFID. Retrieved $21^{\text {st }}$ October 2007 from http://www.ebizq.net/topics/rfid/features/6165.html

Dearne, K. (2006). Bypass queue to see the food. The Australian, 35.

DiSera, M. (2007). A new level of RFID. Design News, 62(15), 23.

Dover, J. (1995). The evolution of the PDF417 communications medium. Logistics Information Management, 8(2), 34-37.

E-Pedigrees, RFID not enough. (2007). Material Handling Management, October, 26-27. 
Fontelera, J. (2007). Quest for the RFID supply-chain holy grail: ROI. Convertingmagazine, September, 35.

Forcino, H. (2004). Getting ready for RFID. Managing Automation, 19, 3-6.

Furness, V. (2005). The RFID market outlook: New applications, best practice and future profit opportunities. Business Insight. Retrieved $16^{\text {th }}$ November 2005 from www.globalbusinessinsights.com/content/rbtc0077t.pdf

Hamblen, M. (2007). Privacy concerns dog IT efforts to implement RFID, ComputerWorld, October, 26.

Ishii, K. (2004). Internet use via mobile phones in Japan [Electronic Version]. Telecommunications Policy, 28(1), 43-58.

Jones, P., Clarke-Hill, C., Comfort, D., Hillier, D., \& Shears, P. (2005). Radio frequency identification and food retailing in the UK. British Food Journal, 107 (6), 356-360.

Jones, P., Clarke-Hill, C., Hillier, D., \& Comfort, D. (2005). The benefits, challenges and impacts of radio frequency identification technology RFID for retailers in the UK. Marketing Intelligence \& Planning, 23 (4), 395-402.

Jones, P., Clarke-Hill, C., Hillier, D., Shears, P., \& Comfort, D. (2004). Radio frequency identification in retailing and privacy and public policy issues. Management Research News, 27 (8/9), 46- 54.

Jones, P., Clarke-Hill, C., Shears, P., Comfort, D., \& Hillier, D. (2004). Radio frequency identification in the UK: Opportunities and challenges. International Journal of Retail and Distribution Management, 32. (3), 164-171.

Karkkainen, M. (2003). Increasing efficiency in the supply chain for short shelf life goods using RFID tagging. International Journal of Retail \& Distribution Management, 31(10), 529-536.

Lai, F., Hutchinson, J., \& Zhang, G. (2005). Radio frequency identification (RFID) in China: Opportunities and challenges. International Journal of Retail \& Distribution Management, 33(12), 905-916.

O’Donnell, P. (2007). RFID - One bit at a time! Manufacturing and Logistics IT Unlimited. Retrieved $7^{\text {th }}$ March 2007 from www.logisticsit.com/absolutenm/templates/? $\mathrm{a}=1760 \& \mathrm{z}=31$

Porter, H. (2006). Surveillance is really getting under my skin. The Observer. Retrieved $18^{\text {th }}$ February 2007 from http://www.guardian.co.uk/commentisfree/story/0,1952010,00.html

Prater, E., Frazier, G., \& Reyes, P. (2005). Future impact of RFID on E-supply chain in grocery retailing. Supply Chain Management: An International Journal, 10(2), 134-142.

Radio Interference. (2007). Baseline, 77.

Ranky, P. (2006). An introduction to radio frequency identification (RFID) methods and solutions. Assembly Automation, 26(1), 28-33.

Reynolds, M. (2007). RFID take-off will not kill the barcode, says experts, Electronics Weekly, Issue 2297, 12.

RFID still brings more questions. (2007). Retrieved November $27^{\text {th }} 2007$ from http://www.purchasing.com/article/CA6458514.html

Sellitto, C., Burgess, S., \& Hawking, P. (2007). Information quality attributes associated with RFID supply chain benefits. Journal of Retail and Distribution Management, 35 (1).

Shaked, D., Levy, A., Baharavl, Z., \& Yen, J., (2001). A visually significant two dimensional barcode. Retrieved $5^{\text {th }}$ December 2007 from www.hpl.hp.com/techreports/2000/HPL-2000-164R1.pdf

Sheffi, Y. (2004). RFID and the innovation cycle, The International Journal of Logistics Management, 15(1), 1-10.

Stevenson, W. J. (2004). Operations management (8th ed.). New York, NY: McGraw-Hill.

Strauch, A. (2007). Securing the hole in RFID security. Wireless Design \& Development, 15, 6. 
Suzuki, L. (2006). The potential of "two-dimensional barcode technology" used in mobile phones as a new means of information provision in the library environment. Retrieved $1^{\text {st }}$ December 2006 from http://conferences.alia.org.au/newlibrarian2006/files/suzuki.pdf

Vijayaraman, B., \& Osyk, A. (2006). An empirical study of RFID implementation in the warehousing industry. The International Journal of Logistics Management, 17(1), 6-20.

Vizard, M. (2007). RFID: What's the real value? Retrieved November $27^{\text {th }} 2007$ from http://www.baselinemag.com/article2/0,1540,2191488,00.asp

Wide ranging barcode scanner - up to 14.6m. (2007). Manufacturers Monthly, September, 78.

Wyld, D. (2006). RFID 101: The next big thing in management. Management Research News, 29(4), 154173.

\section{Biographies}

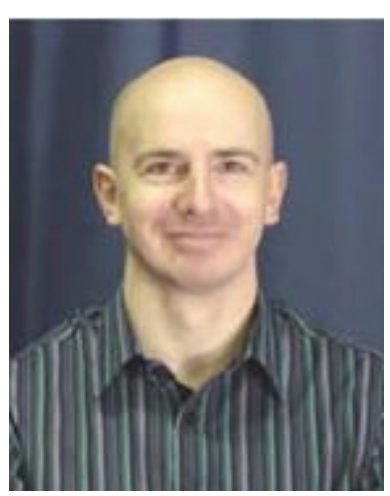

Gareth White is Lecturer of Operations and Information Management in the Bristol Business School at the University of the West of England. His research interests include knowledge creation, organizational improvement, and transdisciplinary investigation that synthesises and shares knowledge across subject and practitioner boundaries.

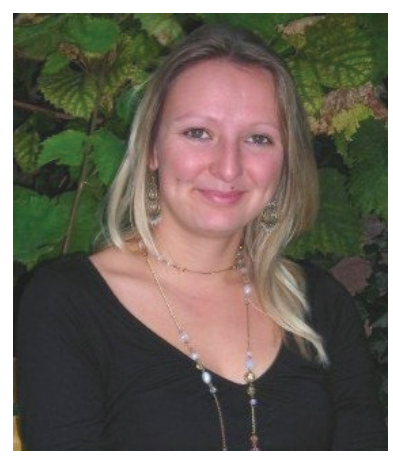

Georgina Gardiner is currently working with one of the UK's largest retail organizations after obtaining her BA Hons in Business Studies with the University of the West of England.

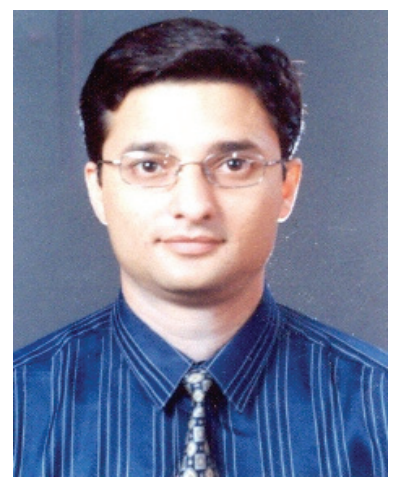

Guru Prakash Prabhakar, Ph.D. (France), PMP (USA), MBA (India), PG-Cert (UK) is Senior Lecturer in the Bristol Business School at the University of the West of England. His research interests include Project Management, leadership and culture. He is engaged in research with the Project Management Institute, USA and ESC-Lille, France. 


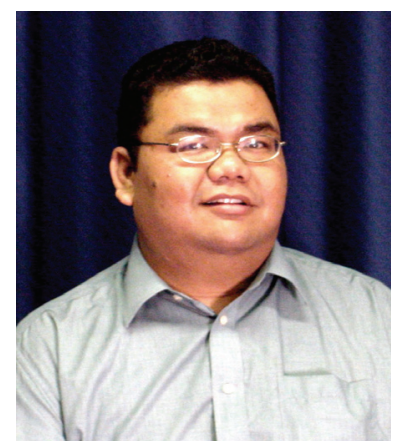

Azley Abd Razak is Research and Teaching Associate in the Bristol Business School at the University of the West of England. His research interests include the Triple Helix model of innovation in developing countries. 